\title{
VECTOR CONTROL SYSTEM DESIGN FOR FOUR DEGREE-OF-FREEDOM DYNAMIC FLEXIBLE SIMULATION OF THE VARIABLE- FREQUENCY DRIVE
}

\author{
Sergey N. Kladiev ${ }^{1 *}$, Anton V. Solozhenko ${ }^{1}$, and Alexander A. Filipas ${ }^{2}$ \\ ${ }^{1}$ Tomsk Polytechnic University, 634050, Tomsk, Russia \\ ${ }^{2}$ Seversk Technological Institute of National Research Nuclear University "MEPhI", 636000, \\ Seversk, Russia
}

\begin{abstract}
In the present work we investigate the control system development of the drive simulators to train driver/operator driving skills, taking into account the ever-changing terrain. In order to meet the required response of the four degree-of-freedom motion platform servomotor current studies have been focused on the vector control of the resistance motor angular velocity from the sensor being incremental encoder. In proposed system the standard security of the frequency converter is realized. It leads to overload capacity of two times within minutes determined by servomotor inertia. Further, we represent the algorithms: positional limitation, reliable acceleration and restraint, frequency break. As well as we demonstrate the position switches implement in software. As a result, the control system commands the control of the angular position of the platform in coordinates.
\end{abstract}

\section{Introduction}

Modern day motion simulator to train professional driver/operators is a hardware and software system and correspondingly, it has complicated structure. This system is based whether on hydraulic drive using the mobile vehicle simulation taking into account the influence of the ground profile, or on frequency-controlled drive using the motion small platform taking into account the dynamic driving modes to train driver/operator driving skills.

\section{Objectives and tasks}

- training of the onset of speed and acceleration signals along axis of rotation of the platforms with motion bases, taking into account the ever-changing terrain;

- allowance for the high load inertia of electric drive;

\footnotetext{
*Corresponding author: kladiev@tpu.ru
} 
- $\quad$ support of the overload capacity of two times determined by servomotor inertia;

- field weakening motor under short-range maintain the torque at the level $0.5 \mathrm{Tn}$.

\section{Subject to control}

The motion platform MP-43 is operated by embedded computer through the local area network, Ethernet- and Modbus TCP-compliant based. The inverter FR-A740 Mitsubishi Electric is used as frequency converter.

Using import component and constituent element in this device lead to vendor lock-in. We mean the foreign suppliers. It takes as point of departure for thinking about industrydomestic concept. It has as a consequence the tasks to upgrade an existing motion platform. Mitsubishi Electric FR-A740 power inverters should be replaced by home. The main objective of the import substitution in regard to such simulators is the program development of microprocessor control systems based on Tomsk research production firm "Mechatronica-pro" hardware and software [1].

\section{Goal of research}

The development of digital microprocessor-based vector control systems for the motion platform drive based on frequency converter FC-01 and CAD MexBIOS Development Studio [1] recommended by embedded software development environment for signal processors Texas Instruments [2].

Hardware component is in the form of the motion platforms DP-43 and four-axis drive. In the present work, we consider one-axis drive constructed as induction motor (IM) integrated into frequency converter FC. We take the parameters of FC output characteristics as technical specification:

Table 1. Technical specification of FC output characteristic.

\begin{tabular}{|c|c|c|c|c|c|c|c|c|c|c|}
\hline $\begin{array}{c}\text { Charact } \\
\text { eristics }\end{array}$ & $\begin{array}{c}\text { Motor } \\
\text { power }\end{array}$ & $\begin{array}{c}\text { Rated } \\
\text { output } \\
\text { current for } \\
2.2 \mathrm{~kW}\end{array}$ & $\begin{array}{c}\text { Overload } \\
\text { capacity } \\
\text { (current) }\end{array}$ & $\begin{array}{c}\text { Output } \\
\text { frequency } \\
\text { range }\end{array}$ & $\begin{array}{c}\text { Frequency } \\
\text { settability }\end{array}$ & $\begin{array}{c}\text { Time of } \\
\text { accelerat } \\
\text { ion / } \\
\text { restraint }\end{array}$ & $\begin{array}{c}\text { Control } \\
\text { strategy }\end{array}$ & Encoder & $\begin{array}{c}\text { Communi } \\
\text { cation } \\
\text { protocol }\end{array}$ & $\begin{array}{c}\text { Limitat } \\
\text { ion of } \\
\text { torque }\end{array}$ \\
\hline Value & $\begin{array}{c}1.1 \mathrm{~kW} ; \\
1.5 \mathrm{~kW} \\
2.2 \mathrm{~kW}\end{array}$ & $5.5 \mathrm{~A}$ & $\begin{array}{c}200 \% / \\
60 \mathrm{~s}\end{array}$ & $\begin{array}{c}0 \ldots 100 \\
\mathrm{~Hz}\end{array}$ & $0.01 \mathrm{~Hz}$ & $\begin{array}{c}0.1 \ldots 100 \\
\mathrm{~s}\end{array}$ & $\begin{array}{l}\text { magnetic flux } \\
\text { vector control } \\
\text { in closed loop } \\
\text { system in } \\
\text { speed [3] }\end{array}$ & $\begin{array}{l}\text { incremental } \\
\text { transducer, } \\
\text { TTL signal } \\
\text { level } \\
\text { between } 512 \\
\text { and 4096 } \\
\text { imp } / \text { rev }\end{array}$ & $\begin{array}{c}\text { Modbus } \\
\text { TCP/IP }\end{array}$ & $\begin{array}{c}0 \ldots 200 \\
\%\end{array}$ \\
\hline
\end{tabular}

\section{The software part}

To create vector control system it has additionally to realize algorithms, providing:

- threshold of current acceleration taking into account the dynamics of transient processes (reverse);

- threshold of breaking for the voltage overloading in the DC link (DC Bus);

- displacement constraint of the electric drive output element position (angular displacement) in the range covered;

- short-range maintain the torque at the selected level $0.7 \mathrm{Tn}$ in the field weakening range between 50 and $100 \mathrm{~Hz}[4,5]$. 
Summarized block scheme of vector control system of frequency converter FC-01 [1] includes: Ramp function - power-up sensor; CUR_MOD - the current-operated model [6,7]; $P I_{-}$- the proportional plus reset controller; IPARC, ICLARC - the Clarke and Park inverse transformations; SAT Irms - the threshold of effective current (saturation); SAT Udc - the safe braking ramp; $U d c$ - the voltage in the FC DC link.

According to the structure of the vector control system described above it differ from widely used systems by presence of the blocks SAT Irms, SAT Udc, Brake, ICLARK. These elements handle follow problems: the threshold of current acceleration; the threshold of acceleration for the voltage overloading in the DC link; the frequency break; specifying the value of voltage to power switch using a third harmonic. It was found that it lead to increase output voltage $15 \%$ The function of block "Brake" is to define « 0 » to the proportional plus reset controller of the speed loop when the displacement constraint of the drive output element occurs [5]. The velocity signals input to the block from the control overhead panel (reff SPD), computer command accept (Start), feedback signal for the speed $\omega^{\bullet}$. Further, if the tripping of the limit switches, which is software-based open, the signal (Start) put into reset state, forming the logical «1» in the block output (RS trigger). Switch $M U X$ changes the state «1» and transfers zero assignment to the speed control unit in the block BRAKE output. The stopping and tripping of the FC run the command from the block (Comparator). The logical «1» in the block output is formed by comparing the feedback signal for the speed « $0 »$ that indicates the drive stopping. Figure 1 present the transient phenomena for the starting of the motor to the minimum ramp control $\omega=0.013$ p.u. $\left(20 \mathrm{~min}^{-1}\right)$ and the step-response time (application of load $2 M_{\mathrm{n}}=30 \mathrm{H} \mathrm{m}$ to motor shaft) at a given time $t=3 \mathrm{~s}$. The off-peak speed is 0.008 p.u. $\left(12 \mathrm{~min}^{-1}\right)$. For disturbance the step-response time does not exceed $\Delta t_{\text {pos }}=0.2 \mathrm{~s}$. The load dump is shown in this figure at the time $t=4 \mathrm{~s}$. In addition, the amplitude quantization is equal $\Delta \omega=0.005$ p.u. $\left(7.5 \mathrm{~min}^{-1}\right)$. It is also was investigated the operating of the motor at the rated speed of the motion platform rotation and the step-response time of the motor (application of load to motor shaft $2 M_{\mathrm{n}}$ at a given time $t=1,5 \mathrm{~s}$ ). Figure 2 illustrates that the off-peak speed does not exceed 0.06 p.u. $\left(9 \mathrm{~min}^{-1}\right)$, the step-response time is not more than 0.25 seconds.

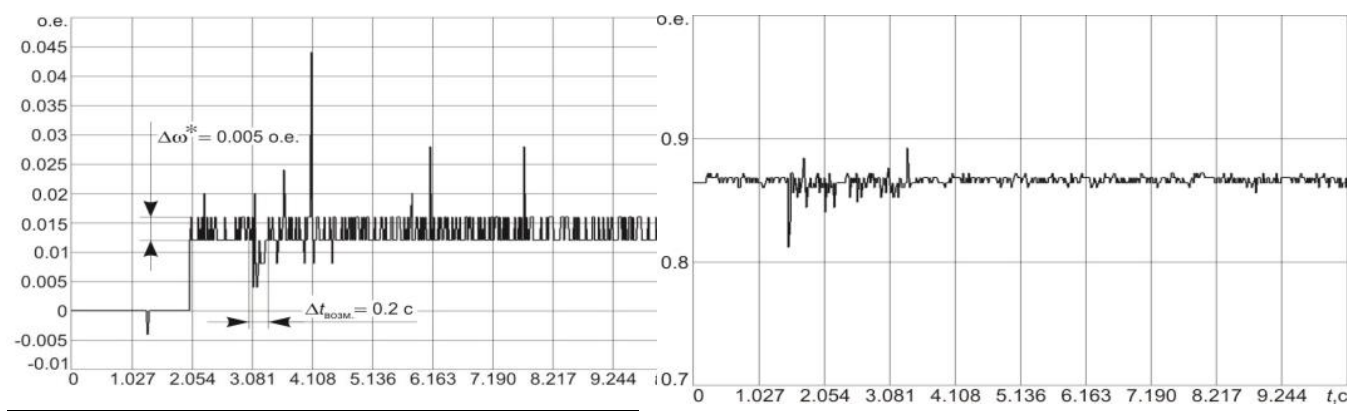

Fig. 1. Starting of the motor idly to the minimum ramp control $\omega=0.013$ p.u. $\left(20 \mathrm{~min}^{-1}\right)$, application of load $2 M_{\mathrm{n}}$ to motor shaft at a given time $t=3 \mathrm{~s}$.
Fig. 2. Transient phenomena for disturbances after application of load $2 M_{\mathrm{n}}$ at a given time $t=1,5$ s speed $\omega=0.86$ p.u. $\left(1200 \mathrm{~min}^{-1}\right)$.

Both figures 3, 4 show results of optimization of the reliable acceleration and restraint states when the motor reverses line power sensor. Applied algorithms of asynchronous motor parameters identification[8] and sensorless vector control[9,10] allows the control system to adapt to the dynamic modes of operation depending on the inertia of the mechanical system. There is an obvious advantage that applied control algorithms intended 
to ensure adapt the control system under dynamic modes according to mechanical system response time. Both threshold parameters which is Isat - the current acceleration, Udc - the voltage of reliable restraint allow threshold of acceleration and jerking of the platform within the prescribed FC limits.

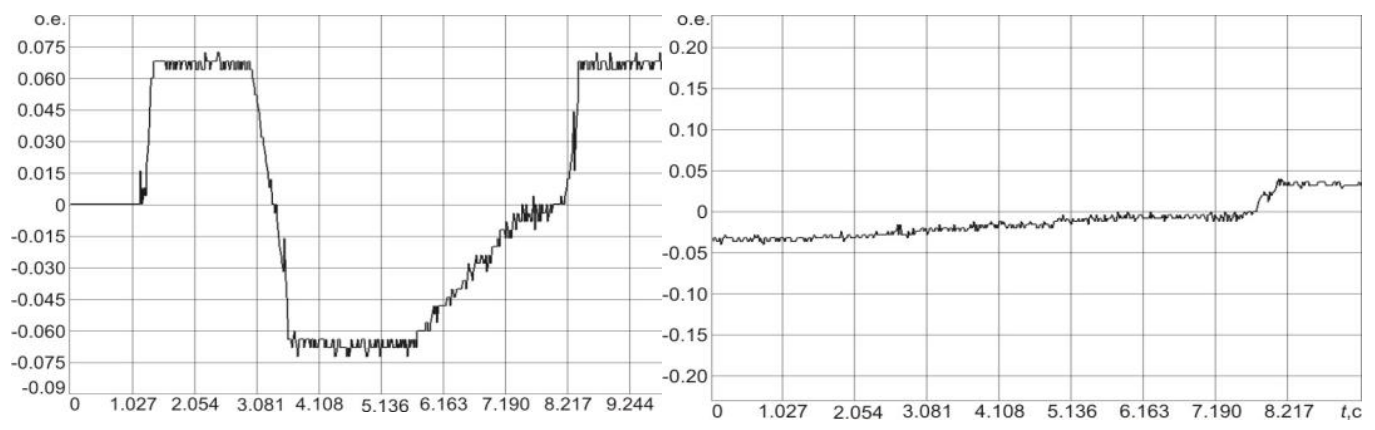

Fig. 3. Acceleration, restraint, reverse on-load $2 M_{\mathrm{n}} ; t_{\mathrm{z}}=0.5 ; \omega=10 \mathrm{~s}^{-1} ; I_{\text {sat }}=5.5 \mathrm{~A} ; U_{d c}=550 \mathrm{~V}$.

Fig. 4. Reverse on-load $2 M_{\mathrm{n}} ; t_{\mathrm{z}}=0.5 ; \omega=10 \mathrm{~s}^{-1}$; $I_{s a t}=4.5 \mathrm{~A} ; U_{d c}=550 \mathrm{~V}$.

\section{Conclusion}

This control system takes into account the allowance for the load inertia of electric drive in the process of speed and acceleration setting, training of the onset of speed and acceleration signals along axis of rotation of the platforms with motion bases, taking into account the ever-changing terrain. In addition, it supports the overload capacitance of two times determined by servomotor inertia. Note that besides the technical specification listed above the control system provides the reliable acceleration and restraint modes, the function of frequency break, the control of the angular position of the platform in coordinates.

\section{References}

1. http://mechatronica-pro.com/en

2. http://www.ti.com/devnet/docs/catalog/embeddedsoftwarefulldetails.tsp?productId=12 220

3. A.S. Anuchin, Control systems of electric drives: textbook for high schools (Publishing House MEI, Moscow, 2015) [in Russian]

4. R.T. Schreiner, Mathematic simulation of the alternating-current drive with semiconductor frequency converters (URB RAS, Ekaterinburg, 2000) [in Russian]

5. D.W. Novotny, T.A. Lipo, Vector Control and Dynamics of AC Drives. (Clarendon Press Oxford, 2003)

6. Peter Vas. Sensorless vector and direct torque control (Oxford University Press, 1998)

7. D.V. Robkanov, Y.N. Dementiev, S.N. Kladiev The 8th Russian - Korean International Symposium on Science and technology Proceedings, 1, 280 (2004)

8. E.V. Bolovin, A.S. Glazyrin, V.N. Brendakov, International Siberian Conference on Russia, 7, 2015 [in Russian]

9. E.A. Kolomiyets; A.Y. Chernyshyov, Int. Sib. Conf. Control Commun., 15287590, 2015

10. V.S., Borisov, N.V. Gusev, P.V. Bykovskih, K.V. Obraztsov, Int. Sib. Conf. Control Commun., 2016 